\title{
What it was like working with Andrew Huxley
}

\author{
Robert Simmons
}

(C) Springer Science+Business Media B.V. 2012

I have often been asked the question: "What was it like working with Andrew Huxley?" It is an ambiguous question-I nearly wrote that it is a specious question but then remembered a meeting of the Physiology Society where a speaker was asked a question, spotted a subterranean issue and stonewalled with "That's a specious question." Andrew Huxley, in the front row as usual, shouted out "There's no such thing as a specious question, only a specious answer!"

'What was it like working with Andrew Huxley?' conflates two questions: 'What were your observations about how he worked?' and 'What did it feel like working with him?' My answer is going to be specious in that I am going to try to avoid answering the second question, at least directly.

I was 30 and 'Prof', as I knew him, was 50 when I went to work with him ('for him' would be more accurate). I had met him 3 years earlier when I was looking for a change of direction-I had a B.Sc. in physics and Ph.D. in protein crystallography. I hadn't achieved much, and he had a Nobel Prize. He had persuaded me to do a two-year M.Sc. conversion course in Physiology at UCL where he was head of department. In the second year I did a project in his laboratory, which went all right, and he took me on in 1967 and arranged for me to be given a temporary lectureship.

Before me in his muscle research had been Rolf Niedergerke, Bob Taylor, Lee Peachey, Al Gordon, Clay Armstrong, Fred Julian. In my time Hugo Gonzales-Serratos (who had been Prof's Ph.D. student) came back for a while; Stuart Taylor and Reinhardt Rüdel came to work on

R. Simmons $(\square)$

Emeritus Professor of Biophysics,

King's College London, London, UK

e-mail: simmons.bob@btinternet.com a separate topic on excitation-contraction coupling - and they went on to do the pioneering experiments on calcium release using aequorin in John Blinks's laboratory. Later Lincoln Ford came to the laboratory and we worked together. I also remember Jan Lännergren coming for a sabbatical, and envying his exquisite dissecting skills. UCL was then a great place for muscle research and biophysics in general, what with Doug Wilkie, Roger Woledge, Brian Jewell and Lucy Brown on the staff in Physiology and Bernard Katz, Ricardo Miledi, Rolf Niedergerke, Sally Page, Gertrude Falk \& Paul Fatt in Biophysics (which had been founded by A. V. Hill). It was a stellar array of talent, past and present.

In my first days in the laboratory, I gathered from Prof that the general idea was to work on the transient mechanical behaviour of stimulated single muscle fibres. It was pretty vague, but I think Prof had the idea that there must be some non-linearity in cross-bridge behaviour and he had a hunch that this would show up in or after rapid changes of length or tension. I also got the impression that something needed to be done to improve the equipment.

My first tasks were to learn single fibre dissection and understand the equipment. Prof demonstrated how to do the dissection - he had a stereo-microscope with two sets of eyepieces for this (see Fig. 1), and gave me a tour of the equipment. There was also a lathe in the laboratory which I was expected to learn to use. For some reason which I cannot remember, Prof was occupied with other things for a while (at that time he was head of department), so I was left to my own devices. The fact is that I had little experience of practical mechanical engineering, electronics and applied physics; there was a little in my Physics degree, but protein crystallography is largely bucket biochemistry to extract your protein and prayer to crystallise it. So the workshop kindly taught me basic machining technique, I 


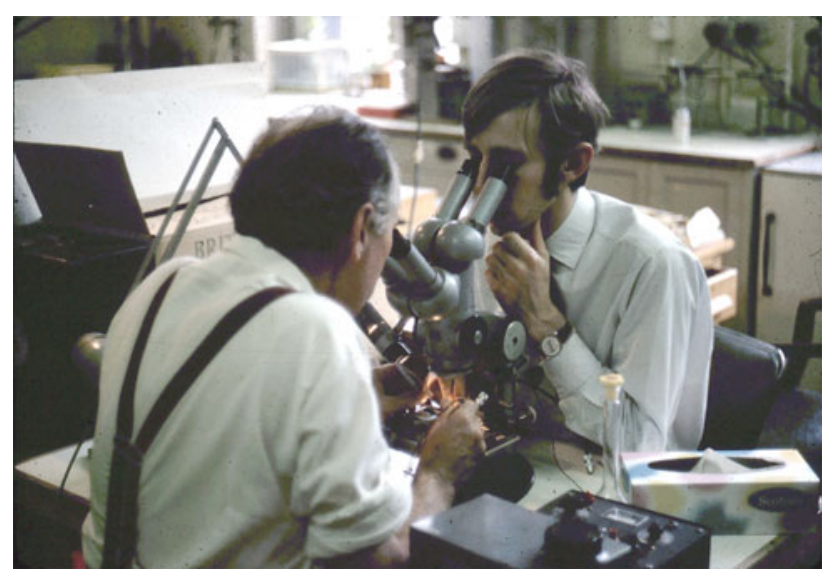

Fig. 1 Andrew Huxley and the author at work, 1969. This photograph was taken by Dr. Stuart R. Taylor and is reproduced with his permission

went on an electronics course, and I taught myself how the Huxley equipment worked.

I remember that early on Prof sent Stuart Taylor and myself down to Sussex to give a demonstration of the dissection technique on closed-circuit TV to a meeting of the Physiological Society. We were barely competent, but that did not seem to worry Prof. It was an interesting experience and we needed a few stiff drinks afterwards! Not long after that Stuart introduced a new chemical to the laboratory fluids cupboard; it was in bottle labelled $\mathrm{BO}_{2} \mathrm{Ze}$ and was dispensed on suitable occasions.

At some point Prof returned to the laboratory and we did some preliminary experiments, repeating what he had done with Fred Julian. The previous experiments looked marvellous to me, for example the work on the relation between length transients and tension transients which had been published in a brief note looked comprehensive, but apparently did not show what Prof was looking for. Then there were experiments on rapidly overloaded fibres, in which there is a 'pull-out' phenomenon (rapid lengthening), but Prof didn't like these as the effect was variable and he couldn't understand what terminated the pull-out, so we abandoned the study.

We agonised for some time whether it was better to use length steps or tension steps as the perturbation. Tension steps were in some ways preferable but technically more demanding as the properties of the fibre are included in the servo-loop, and a square wave input came out looking quite wobbly. But we pursued tension steps for a while and during this time there came the opportunity to see Prof working on something himself. The idea was to take out all the wobbles in the tension record by feeding in a square wave that had an appropriate inverse shape. We didn't have a computer and Prof decided to build a follower device. He took an oscilloscope and modified it so that the beam followed round the profile of an opaque piece of card lodged against the screen, using feedback from a photocell. Starting with a Polaroid of the actual applied tension step, he measured some parameters of the wobbles, did some kind of deconvolution to get out the appropriate shaped input to counter the wobbles, which he cut out of card with a pair of scissors. It was a tour de force. I think I managed to understand how he did the deconvolution but it always came out wrong when I did it and my skill with scissors was below par. It didn't work in the end because of the non-linearities of the muscle fibre, and we used length steps from then on.

In 1969 Prof was awarded a Royal Society Research Professorship and had more time for research. At this stage we analysed our data on length steps and we observed the following: after a rapid length change the resulting tension transients were much the same during the rise of tension as in the plateau of a tetanus; imposed during shortening they became faster and stiffer in relation to tension; stiffness did not change much during the initial recovery transient. Supposing that this phase were to be generated by some structural property of attached cross-bridges, what kind of model would explain it?

This was an unusual period when we had frequent and intensive discussions about the model—usually Prof liked to go away and think about such things on his own. I think it was because he sensed that he had got to a point where a model might emerge, but for some reason needed an external stimulus. I do remember we arrived at a formal explanation in terms of standard viscoelastic elements, favouring a Voigt model - an undamped elasticity in series with a damped element with a restricted range of movement of around $10 \mathrm{~nm}$ (about right for a cross-bridge stroke, a myosin head rotating about its point of attachment to an actin filament), but there was a difficulty in explaining the dependence of the time course of recovery and we seemed to be stuck. One Monday morning Prof came in looking excited and said 'I think I understand how it works' and produced the elements of a model involving a force-dependent equilibrium constant between two mechanical states. This became the Huxley-Simmons model, in truth about $90 \%$ Huxley $10 \%$ Simmons.

In retrospect I think Prof must have got the idea from the kinetic approach which Alan Hodgkin and he had used to explaining the action potential in the squid giant axon where they had introduced voltage-sensitive rate constants. There was also some prior work on long-short transitions in polymers and I remember spending a sweltering summer's day searching for obscure references in the extraordinary conservatory-like library of the Patent Office, which was the only place in the UK which held the Australian Wool Gatherer's Gazette (or whatever it was called). Terrell Hill, who later wrote a thermodynamically correct approach to 
the cross-bridge cycle (and became a great friend), told me much later (rather stiffly I thought) that the same idea was embedded in a paper of his in the 1960s and I duly read it several times, but could not fathom what he meant. I also remember being deputed to gain some insight into molecular models via Eyring's absolute rate theory and ending up with a headache.

The kinds of experiments that needed to be done were now clear, but there were several obstacles. The equipment was too slow-much of the fastest transient was lost-and we first tried out fibres from a number of different species whose muscles had been claimed to be slower than in frog. This was a good excuse for an excursion for Lincoln and myself to try out some fish muscles at the Marine Biology Laboratory in Plymouth where of course Hodgkin and Huxley had done their squid axon experiments. Unfortunately the muscles turned out to be either similar in speed to frog muscle or, if slower, were impossible to dissect.

So we had to speed up the equipment and improve techniques in a number of ways. I had already made a new tension transducer. Prof had worked out the principles of a capacitance gauge design, and I built this under his tutelage, using a glass strip for its thermal properties and mounted a defined distance from a glass support to get critical damping. Prof was amazingly knowledgeable and keen that I should explore every aspect of the potential materials and the technique; by the end I could have written a book about everything I tried.

We also needed a faster motor and though I tinkered unsuccessfully with a commercial servo-motor, Lincoln set to work building a novel moving-coil design of Prof's using a strip-hinge mounting for the coil. I remember wondering how Lincoln would get on as he had little physics but he did a brilliant job and managed all the technical stuff to boot. I remember there was a very clever dodge to eliminate eddy currents which involved sticking a layer of copper on the magnet.

For technical reasons we needed to improve the way the fibre was mounted. The photograph of Prof and myself was taken by Stuart Taylor and shows us trying to tie the tendons at the end of a muscle fibre on to hooks. This didn't work very well and in the end, and I think it was Lincoln who suggested it, we crimped a piece of aluminium foil on to the tendon.

Prof himself worked on the spot-follower apparatus, which monitored the distance between two 'flags' attached along the length of a fibre, thus in principle eliminating issues resulting from differences in the sarcomeres at the ends, and also taking out any residual end-compliance in the tendons. This apparatus was a source of constant trouble and resulted in the premature demise of many a fibre as it went out of control and pulled the fibre apart.

Finally when the equipment was built we did the major experiments. We worked long hours. It fell to me to do the dissection and the setting up of the fibre first thing in the morning while Lincoln and Prof tuned up the gear. If a fibre survived we would go on until it died, often all night and well into the next day. We were fuelled by hamburgers and fries from a Wimpy Bar, and there were cups of tea and coffee and biscuits 'to keep the blood sugar up'.

There wasn't much room near the equipment so we stood up most of the time. If something went wrong or the electronics needed a tweak, Prof would just stand there thinking it out, eyes half-closed. I wondered whether he was writing on his mind, as it were, or if he was summoning up some occult power, but didn't like to ask.

Writing up was something else. Lincoln had moved to Chicago but made a number of visits back to analyse the data; there was a lot of it and what he did was heroic. But progress was painfully slow: the first paper, which described the general mechanics of transients and their interpretation, had some theory that only someone with a brain like Prof's could manage, and he had an extraordinary analogue simulator built to aid the analysis. The subsequent papers were thankfully more straightforward and I even managed to do some of the theory. I knew instinctively when I handed it to Prof that he would find a more elegant way to do the maths and I was not disappointed.

Prof lived just outside in Cambridge (and had lodgings in Gower Street during the week). My wife and I were invited to his house on a number of occasions and got to know his wife Richenda, a wonderfully warm woman. We hadn't been married that long and my wife remembers Richenda gently breaking it to her what it meant to be married to a scientist. Through visits to Cambridge I gained some insight into Prof's relationship with the other Cambridge physiologists; I remember being introduced to A. V. Hill, William Rushton, Richard Keynes and Richard Adrian, though I never met Alan Hodgkin. There was a good deal of Cambridge banter and intellectual sparring, but I noticed there was an underlying respect for and deference to Prof; and quite right too I thought.

Among his many acts of kindness and generosity I remember two in particular. The first happened when I had bought an old house and ran out of money for refurbishment; he offered to lend me what he had left over from his Nobel Prize (and I have to admit to wondering rather wickedly whether I could put on my CV 'shared the Nobel Prize'). The second was when I started up on my own; he lent me his laboratory and equipment until I found my feet.

What was it like working with Prof? I had the illusion sometimes that I was keeping up with him, but this was when I was running and he was walking; when he started running I lagged a long way behind. I sometimes said he had an extra gear, but it was more like an afterburner; when this cut in, he was off into the distance and one was left standing. 